\title{
Different types of tissue composition in inflammatory or reparative upper airway disorders*
}

\author{
Laurence De Coster ${ }^{1}$, Philippe Eloy ${ }^{2}$, Liesbeth Ferdinande ${ }^{3}$, Jasmien \\ Taildeman³, Claude A. Cuvelier ${ }^{3}$, Jean-Baptiste Watelet ${ }^{1}$ \\ Department of Otorhinolaryngology, Ghent University, Ghent, Belgium \\ Department of Otorhinolaryngology, CHU Mont-Godinne UCL, Belgium \\ Department of Pathology, Ghent University, Ghent, Belgium
}

Rhinology 50: 393-401, 2012

DOI:10.4193/Rhino11.164

*Received for publication:

August 12, 2011

Accepted: August 9, 2012

\section{SUMMARY}

Background: Composition changes of extracellular matrix (ECM) can lead to functional disorders of the upper airways (UA). The aim of this study was to systematically measure both the association patterns and the correlation degree between tissue composition parameters in UA inflammatory diseases.

Methodology: Nasal samples were obtained from patients with chronic rhinosinusitis with (CRS+NP), without nasal polyps (CRS), with post-operative adhesions (S) and normal nasal mucosa (NM). A reproducible semi-quantitative method, which takes epithelial and lamina propria damages into account was applied for haematoxylin and eosin, alpha-smooth muscle actin, reticulin, elastin, laminin and collagen type IV stainings.

Results: The most severe cases of epithelial shedding have been found in a significant higher amount in CRS+NP when compared with NM. The most severe cases of inflammatory reaction were mainly found in CRS+NP. CRS+NP had significantly more severe cases of oedema than NM. Excluding elastin, networks in other ECM proteins were found modified in fibrotic fields but to a lesser extend in oedematous regions in all conditions.

Conclusion: Although non specific, oedema in the lamina propria is a key-feature of CRS+NP, while fibrosis, massively present in CRS and S, affects profoundly the distribution of ECM proteins in these areas.

Key words: upper airways, chronic rhinosinusitis, nasal polyps, epithelium, extracellular matrix

\section{Introduction}

An adequate interaction between all anatomical and histological components of the nasal and paranasal cavities is necessary for ensuring the protective properties of the nose ${ }^{(1,2)}$. The nasal pseudostratified columnar epithelium (respiratory epithelium) is separated from the lamina propria by a continuous basement membrane and a contingent of resident, inflammatory cells. The subepithelial region contains seromucous glands, blood vessels and a supporting connective tissue of loose type, which plays an essential role in inflammatory reactions but can also be the site of structural changes during chronic inflammations.

Remodelling is defined as a process leading to transient or permanent changes in tissue architecture, which involves breakdown of tissue structures as well as repair ${ }^{(3,4)}$. During normal wound healing of the upper airways, it has been established that extensive oedema and fibrosis in nasal lamina propria appear and diminish in a well-coordinated sequential manner ${ }^{(5)}$. However, changes in the composition of extracellular matrix (ECM) can lead to functional disorders and are suspected to 
maintain the inflammatory statute inside the mucosa. Furthermore, tissue changes interfere significantly with the responsiveness to medical therapies, making the protective or deleterious role of changes in airway tissue structure largely debated ${ }^{(6)}$.

In human and animal models, mucosal damages, such as epithelial shedding, thickening of basement membrane, fibrosis, have been regarded as important histomorphological features of chronic rhinosinusitis ${ }^{(7-9)}$.

Several ECM proteins have been the scope of recent publications on tissue composition in airway chronic inflammation. Elastic fibres are ensuring tissue elasticity. Type-IV collagen is primarily found in the basal lamina and could function as filtration system. Reticulin or reticular fibres is a type of ECM fibre closely related to type-III collagen in composition. The laminins are an important and biologically active part of the basal lamina, influencing cell differentiation, migration, adhesion as well as phenotype and survival ${ }^{(10)}$. Finally, besides the ECM proteins, the expression of alpha-Smooth Muscle Actin ( $\alpha$-SMA) correlates with the activation of myofibroblasts, which are known to play a key role in the development of fibrotic responses ${ }^{(11)}$.

The respective proportion of the specific epithelial and ECM composition features remains largely unknown in chronic upper airway diseases. To have an indirect view on the dynamic and long-during remodelling process, the aim of this study was to systematically describe its end results through the analysis of major histomorphological damages, fibroplasia and neoangiogenesis in tissue samples from chronic rhinosinusitis with (CRS+NP) and without nasal polyps (CRS), in post-operative adhesions (or synechiae) (S) in comparison with normal mucosa. Finally, the expression and distribution of laminin, reticulin, elastin, alpha-smooth muscle actin and type IV-collagen was analysed on all tissue samples.

\section{Materials and methods}

\section{Materials}

Nasal biopsies were obtained in patients operated by FESS at the department of Otorhinolaryngology, University Hospital Mont-Godinne UCL, Belgium. Nasal samples were obtained from patients with CRS+NP $(n=10)$ and CRS $(n=10)$ and from patients with post-operative $S(n=10)$ during routine nasal and sinus surgery. Samples from CRS and CRS+NP were obtained at the level of ethmoid sinus cavities, while samples from synechia were obtained from the resection piece. These patients were operated after failure of appropriate medical treatment. Medical systemic and local treatment was stopped two weeks before surgery. Ten subjects with normal nasal mucosa were considered as controls. The normal mucosa obtained in controls, was biopted at the level of the inferior turbinate. At the moment of surgery, they were free of any acute or chronic nasal or sinus dis- eases and were operated for snoring or lachrymal duct pathologies. All patients and controls were non-smokers.

Allergy was explored in all cases by use of Skin Prick Test. If these tests were negative and if the history was suggestive for this condition, complementary RAST were performed. However, the patients presenting positive allergy tests were not considered as normal controls.

With regard to NSAID intolerance, the identification was done on history basis. No systematic provocation test was performed.

\section{Methods}

Preparation of sections. Fresh surgical resection specimens of human nasal tissues were collected and immediately fixed in $4 \%$ buffered formalin (Labonord, Templemars, France). After embedding in paraffin, five-micron sections were cut and mounted on slides.

Histochemistry. Next sections were dewaxed and rehydrated in graded alcohols. For the haematoxylin-eosin staining, slides were immersed in Gills haematoxylin solution (Merck, Darmstadt, Germany) for $2 \times 4$ minutes. After washing in running tapwater, sections were dipped in a $\mathrm{HCl}$ solution and submerged for 3 minutes in a 1\% eosin solution (Merck). Sections were then dehydrated and mounted (Sakura, Zoeterwoude, The Netherlands).

The stainings for elastin and reticulin were performed manually according to Van Gieson and Gomori, respectively. For elastin staining, sections were stained using the Elastica van Gieson staining kit (Merck). Briefly, sections were immersed in an elastin solution for 10 minutes. After washing in running tapwater, sections were submerged for 5 minutes in a haematoxylin iron nitrate solution followed by 2 minutes in a picrofuchsin solution after washing. Sections were then dehydrated and mounted with Tissue-Tek (Sakura). For reticulin staining, slides were dipped in a kalium permanganate solution for 12 minutes followed by washing in running tap water for 3 minutes. Then, slices were submerged for 4 minutes in a kalium metabisulfite solution and washed again after which sections were immersed for 6 minutes in an iron aluin solution. Next, a silver solution was applied ( $1 \mathrm{~min}$ ) followed by formaldehyde ( $5 \mathrm{~min}$ ), gold chloride (10 min), kalium metabisulfite (4 min), natrium thiosulphate (1 min) and kernechtred for 5 minutes. Afterwards, sections were dehydrated and mounted.

Immunohistochemistry. The immunohistochemical stainings were performed on the Ventana automated immunostainer with the Ventana iView DAB detection kit (Ventana Medical Systems, Strasbourg, France) using the peroxidase anti-peroxidase technique. Briefly, tissue sections were deparaffinized, rehydrated, and antigen retrieval was performed for laminin (protease pretreatment) and collagen type IV (0,01 M citrate ( $\mathrm{pH} 6)$ pre-treatment) 
staining. After blocking of aspecific peroxidase staining, primary antibodies were applied for 30 minutes (a SMA: 1/40, Biogenex MU128-UC, San Raman, California, USA; Laminin: 1/15, Biogenex PU078-UP; Collagen type IV: 1/20, DAKO M0785, Glostrup, Denmark). Next, biotinylated secondary antibodies were applied, followed by HRP-conjugated streptavidin. Immunostaining was finally visualized using 3,3'- diaminobenzidine as a chromogen (DAKO), and haematoxylin as a counter stain.

Quantification. A reproducible semi-quantitative method, which takes both staining percentage and intensity into account, was applied in haematoxylin and eosin, alpha-smooth muscle actin, reticulin, elastin, laminin and collagen type IV stainings.

All parameters were scored semi-quantitatively on a four-point scale ${ }^{(12)}$ by a senior pathologist (CC), who was blinded for diagnosis and clinical data. Zero represented the lowest (absent) and three the highest score (severe). As some histological markers were more abundant than others in normal nasal mucosa, the scoring system was calibrated for each marker independently by examining a representative number of samples.

Epithelial shedding was characterized in function of the length of basal cells or basement membrane uncovered by epithelial cells. The thickness of the basement membrane was determined as average of measurements in sections where the epithelium was properly oriented to avoid artifacts in measurement. Cells and ECM deposition were analyzed separately in different compartments, in epithelium, around glands, blood vessels and in lamina propria. The connective tissue, when possible, oedematous and fibrotic regions, fibroplastic and endothelial proliferation were also considered independently. The analysis included all areas of the biopsies and both a specific and global score were given for each parameter. Both the distribution and degree of severity of the histomorphological parameters were studied.

\section{Statistical analysis}

Statistical analysis was performed with SPSS 11.0 (SPSS Inc., Chicago, IL, USA). In function of the parameters, the non-parametric Mann Whitney $U$ test or Chi-square were used to analyse the difference between groups. Correlations were described with their Spearman correlation coefficient $r$ and their $p$ value.

A post-hoc adjusted statistical difference of $p<0.05$ was regarded as significant.

This study was approved by the ethics committee of the faculty of Medicine and Health Sciences of University Hospital MontGodinne UCL (nr 58-2004).

\section{Results}

The mean age was 51.2 years with range from 18 to 79 years. The gender proportion was 15 males and 25 females. In the disease groups, $20 \%$ of patients were found sensitized for the most frequent aeroallergens (house dust mites, tree and grass pollens, animal danders) and $20 \%$ suffered from asthma. Two patients suffered from COPD and one had aspirin intolerance. Sensitization to aeroallergens and lower airway diseases were not found in the control group.

\section{Histomorphological findings by Haematoxylin Eosin}

1.a. Structural tissue. Epithelial shedding was found in all pathologic conditions and, in normal mucosa, only mild cases were observed. Moderate and severe cases were mainly found in CRS+NP and other pathologic conditions when compared to normal mucosa (Chi-square $=14.400, \mathrm{p}<0.0001$ ) (Figure 1a). The most severe cases of epithelial shedding have been found in a significant higher amount in CRS+NP when compared with normal mucosa $(p=0.029)$. However, the thickness of the basement membrane was not found significantly different between pathologic conditions.

Gland atrophy was found to vary significantly between the disease conditions (Chi-square $=6.400, p=0.011$ ) but was not found in normal mucosa. When compared with normal mucosa, gland atrophy was found mainly increased in samples from $C R S+N P(p=0.029)$ and from $S(p=0.012)$ (Figure $1 b)$.

Signs of neoangiogenesis were only found in abnormal amount in the different disease conditions but not in normal mucosa. Even present in variable amounts between samples (Chi-square $=22.500, p<0.0001$ ), it was mainly found in S (Figure 1c). On the other hand, samples with extensive network of capillaries in the lamina propria were mainly observed in CRS+NP and CRS (Chisquare $=6.400, p=0.011$ )

1.b. Inflammatory reaction. The severity of inflammatory reaction was found significantly different between the different conditions (Chi-square $=6.350, p=0.042$ ) and the most severe cases were mainly found in CRS+NP. On HE staining, eosinophils, neutrophils, lymphocytes, and mast cells were not found to be significantly different between groups but plasma cells were found in significantly higher number in CRS+NP when compared to normal mucosa $(p=0.029)$. The presence of lymphoid follicles in the lamina propria was found different between pathological samples (Chi-square $=16.900, \mathrm{p}<0.0001$ ) and was mainly detected in CRS (Figure 1d).

1.c. Connective tissue. Chronic rhinosinusitis with nasal polyps had significantly more severe cases of oedema than NM $(p=0.009)$ (Figure 2a). CRS+NP were found to have less cases presenting fibrosis in lamina propria (Chi-square $=14.400, p<$ 0.0001 ) than other inflammatory conditions. Most severe cases of fibrosis were mainly found in $\mathrm{S}$ but this increase did not reach statistical significance when compared with the other conditions (Figure 2b). Fibroplasia was found significantly different between the disease groups, with more severe cases in CRS+NP and $\mathrm{S}$ (Chi-square $=20.600, \mathrm{p}<0.0001$ ). 
Table 1. Major histomorphological findings.

\begin{tabular}{|c|c|c|c|c|}
\hline Parameters & Nature & CRS & CRS+NP & $\mathbf{S}$ \\
\hline Epithelium & $\begin{array}{c}\text { More severe cases } \\
\text { of: }\end{array}$ & & $\begin{array}{l}\text { - Epithelial shedding } \\
\text { - Gland atrophy }\end{array}$ & Gland atrophy \\
\hline Blood vessels & $\begin{array}{c}\text { More severe cases } \\
\text { of: }\end{array}$ & Exclusive capillaries & Exclusive capillaries & Neoangiogenesis \\
\hline $\begin{array}{l}\text { Inflammatory reac- } \\
\text { tion }\end{array}$ & $\begin{array}{c}\text { More severe cases } \\
\text { of: }\end{array}$ & Lymphoid follicles & Overall inflammation & Accumulation of plasma cells \\
\hline \multirow[t]{3}{*}{ ECM } & $\begin{array}{c}\text { More severe cases } \\
\text { of: }\end{array}$ & & $\begin{array}{l}\text { - Oedema } \\
\text { - Fibroplasia }\end{array}$ & Fibroplasia \\
\hline & Less cases of: & & - Fibrosis & \\
\hline & Trend for: & Reduction of aSMA+ & $\begin{array}{l}\text { - Reduction of aSMA+ } \\
\text { - Decreased density of } \\
\text { reticulin network }\end{array}$ & $\begin{array}{c}\text { - Fibrosis } \\
\text { - Decreased density of reticulin } \\
\text { network }\end{array}$ \\
\hline
\end{tabular}

Legend: CRS-NP: chronic rhinosinusitis without nasal polyps; CRS+NP: chronic rhinosinusitis with nasal polyps; S: synechiae (adhesions); ECM: extracellular matrix; aSMA: alpha-smooth muscle actin

a

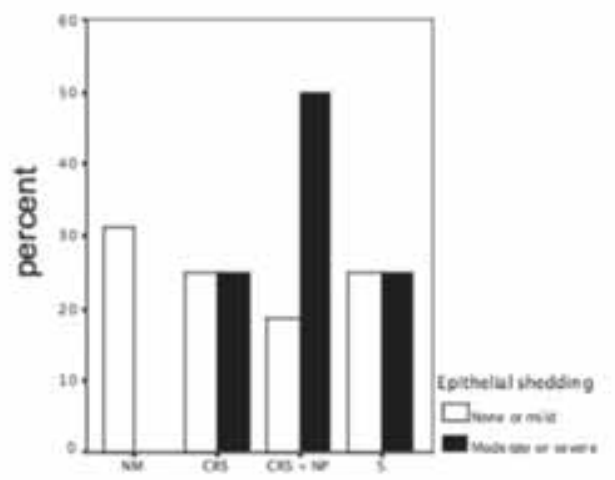

C

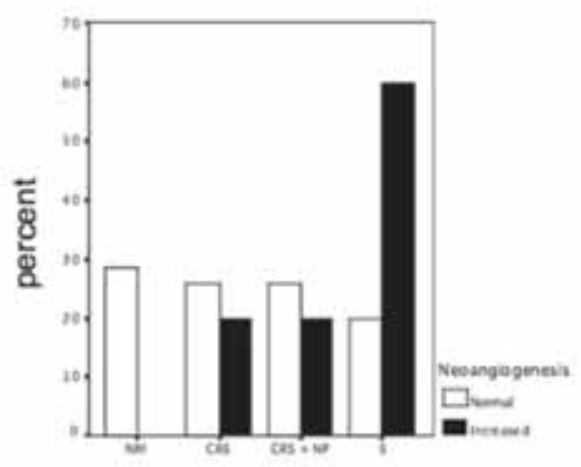

b

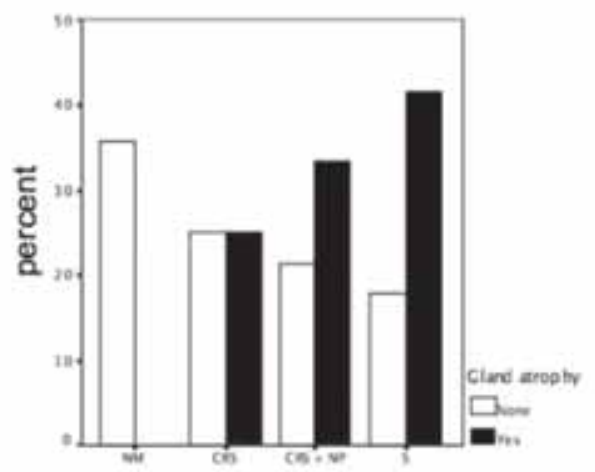

d

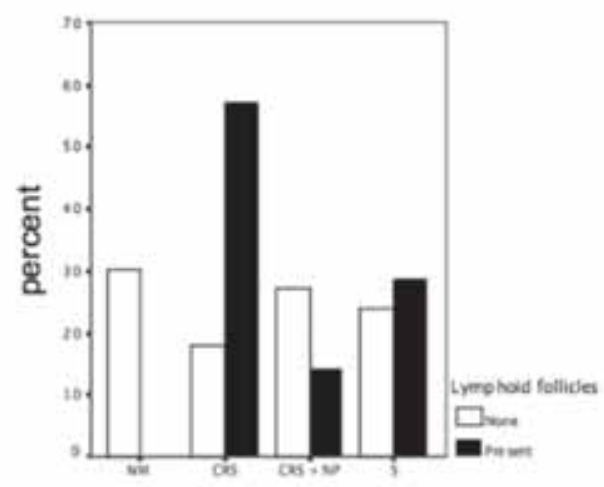

Figure 1. Structural changes of nasal mucosa in normal and abnormal conditions.

NM: normal mucosa; CRS: chronic rhinosinusitis without nasal polyps; CRS+NP: chronic rhinosinusitis with nasal polyps; S: synechiae. Severity of a) Epithelial shedding, b) Gland atrophy, c) Neoangiogenesis, d) Presence of lymphoid follicles. 


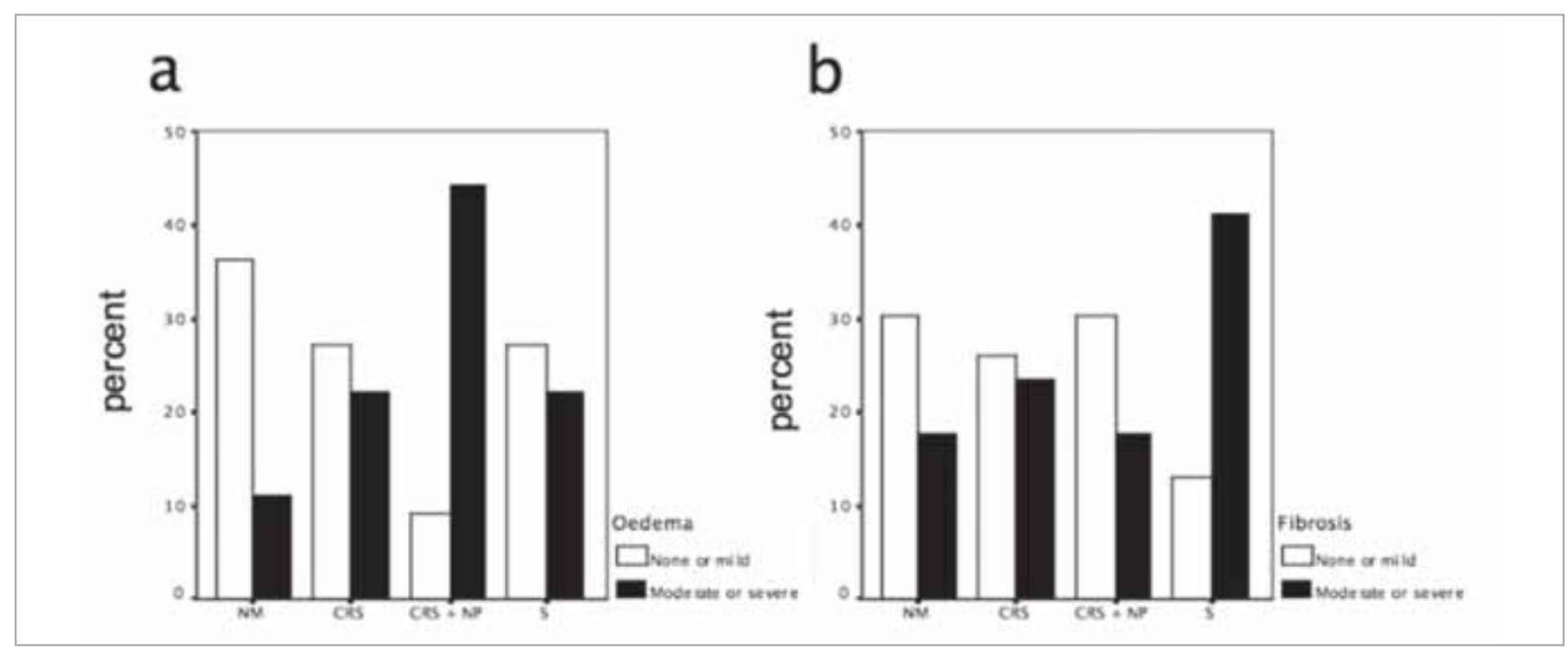

Figure 2. Extracellular Matrix Composition in normal and abnormal conditions.

Comparison between normal mucosa (NM), chronic rhinosinusitis without nasal polyps (CRS), chronic rhinosinusitis with nasal polyps (CRS+NP) and adhesions or synechiae (S). Severity of a) Oedema, b) Fibrosis.

Table 1 shows a summary of the histomorphological findings in the different groups found in this study.

\section{Histochemistry}

2.a. Reticulin. Changes in distribution or intensity of reticulin network were not correlated with the type of upper airway disease. However, there was a non-significant trend in CRS+NP and $\mathrm{S}$ to present reduced or absent reticulin network in the subepithelial region (Chi-square $=5.150, \mathrm{p}=0.071$ ).

2.b. Elastin. Elastin was found in all the walls of blood vessels. Elastin deposition was not found changed in fibrotic or oedematous regions. Elastin network was found respected in all pathologic conditions, without any significant differences between them.

\section{Immuno-histochemistry}

3.a. Alpha smooth muscle actin. No difference between diseases was observed in expression of aSMA in vessels. In normal mucosa, the majority of samples had a non-significant tendency to present moderate or high amounts of aSMA-positive cells while, in CRS+NP or CRS, none or few aSMA-positive cells were found (Chi-square $=3.600, \mathrm{p}=0.058$ ).

\section{3.b. Laminin. Laminin was present in blood vessels of all} samples. In regions presenting fibrosis, staining of laminin was observable but not in oedematous field. The different diseases conditions did not show significant differences.

\section{3.c. Type IV collagen. Staining for type IV collagen was mainly} found in the basement membrane, blood vessels, and fibrotic fields. No significant difference was found between the groups. In oedematous regions, type IV collagen was poorly distributed.
Figures 3 illustrates tissue composition characteristics of CRS and CRS+NP, while Figure 4 reports ECM protein expression in fibrotic and oedematous fields.

\section{Discussion}

Even if CRS+NP and S present predominant oedematous and fibrotic patterns, respectively, this study demonstrated that many aspects of changes in tissue composition are not specific of these upper airway diseases and can present a wide range of severity.

In this cross-sectional analysis, we explored only the end results of the tissue remodelling process, which, for being completely addressed, should benefit of a longitudinal study design.

The first innovative observation is that tissue changes can affect nearly all types of chronic inflammatory diseases in upper airways, although with different degree of severity and many similarities with ECM changes in asthma have been observed ${ }^{(13,14)}$. In vasomotoric and allergic rhinitis, changes in tissue composition appears to be more limited ${ }^{(15-17)}$. Epithelial shedding can accompany clinical response to cold, dry air or to urban pollution (18). A second important finding is the confirmation of the close link between inflammatory reaction and extensive variations in ECM composition, which has been confirmed in this study. Lymphoid follicles are regularly found in chronic inflammatory processes in upper airways ${ }^{(19)}$. Oedema is regularly found associated with a severe local inflammatory reaction, probably through a local activation of fibroblast matrix metalloproteinases by inflammatory cells ${ }^{(20)}$. Finally, as demonstrated for the first time in this study, lymphoid follicles were mainly found in lamina propria of CRS samples and absent in normal tissue samples.

The third essential observation of this study is the confirmation that all histomorphological changes are not specific of a particu- 


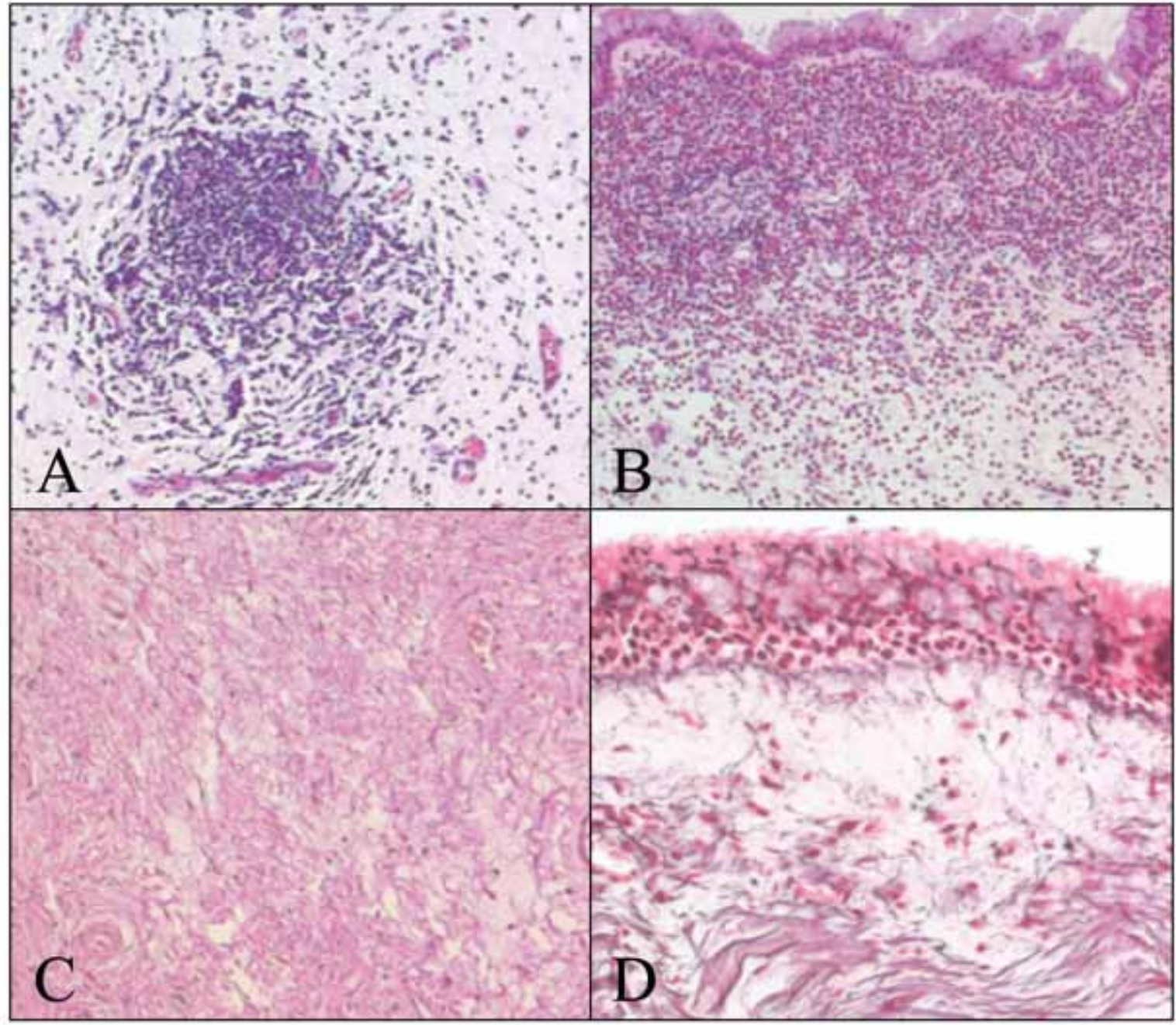

Figure 3. Comparison between chronic rhinosinusitis with or without nasal polyps.

a) CRS: lymphoid follicles (HES X 100); b) CRS+NP: severe subepithelial inflammatory reaction and oedematous lamina propria (HES X 100); c) CRS+NP: intact elastin network in oedematous fields (Elastin X 100); d) CRS+NP: reduced subepithelial network of reticulin (Reticulin X 200).

lar chronic upper airway disease. With regard to the epithelial changes, Ponikau et al., have reported that epithelial damage was observed in tissue from refractory CRS ${ }^{(21)}$. The basement membrane thickening and the mean grade of sub-epithelial collagen deposition are significantly higher in CRS as compared to controls ${ }^{(22)}$. It has been recently suggested that the increased basement membrane was correlated with prolonged duration of sinus symptoms and the coincidence of asthma ${ }^{(23,24)}$. Regarding the respiratory epithelium, nasal polyps show a diversity of histological changes including hyperplasia, atrophy or squamous metaplasia, and goblet cell hypertrophy ${ }^{(25,26)}$. On the other hand, basement membrane thickening and epithelial damage, has been shown correlated to the local infiltration of eosinophils ${ }^{(27)}$ and IL-17A-positive cells ${ }^{(28)}$. In our study, the thickening of the basement membrane was not found specifically linked to a sub- group of chronic inflammatory diseases of the upper airways, independently of their allergic or asthmatic background. Another important observation is that, in contrast with the epithelial changes, the major damages observed at the subepithelial level seem to be more closely linked to specific inflammatory nasal or paranasal pathologies ${ }^{(29)}$ extensive oedema in CRS+NP, extensive fibrosis in S and a combination of oedema and fibrosis in CRS. As already demonstrated in earlier histomorphological studies, in CRS+NP with or without cystic fibrosis, the lamina propria presents major oedema ${ }^{(30)}$, which is considered as discriminative of CRS+NP against other types of CRS ${ }^{(31)}$ and which is probably mediated by a large amount of cytokines and enzymes ${ }^{(32-34)}$. Interestingly, the absence of neoangiogenesis

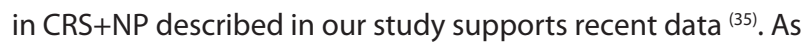
demonstrated here, all components of the ECM, but elastin are 


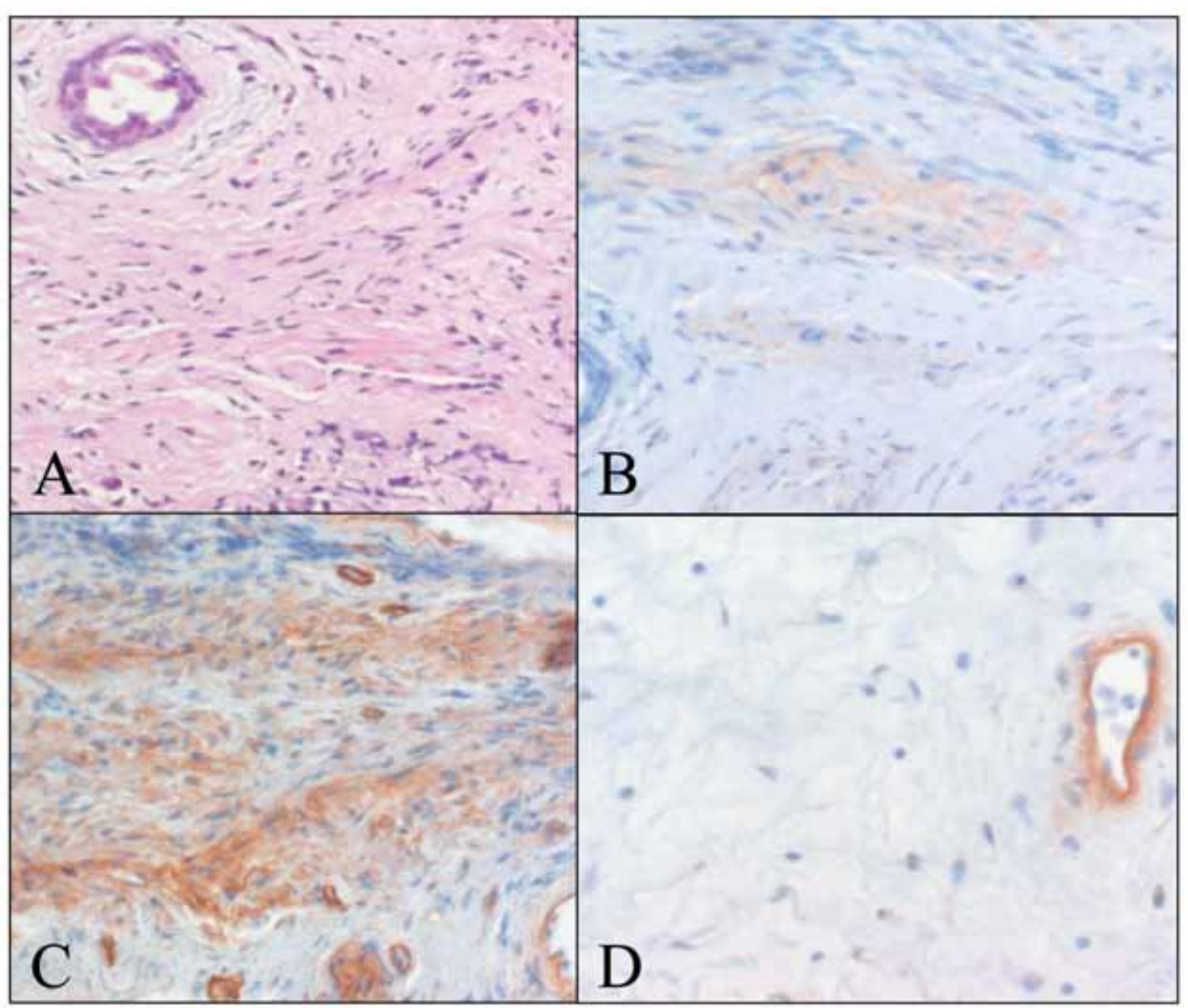

Figure 4. Fibrotic and oedematous fields.

a) Adhesion: fibrosis, fibroplasia and neoangiogenesis (HES X 200); b) Adhesion: type IV collagen deposition (Type collagen staining X 200); c) CRS: laminin in fibrotic regions (Laminin X 200); d) CRS+NP: absence of laminin in oedematous regions (Laminin X 200).

affected by the plasma exudation and pseudocyst formation. The distribution of elastin seems to be less affected by oedema probably because of its physico-chemical properties ${ }^{(36)}$. The oedematous regions in both CRS and CRS+NP were found poor in aSMA-positive cells. This finding confirms the observation of Nishijima et al. showing that the distribution of aSMA-positive cells tended to be more remarkable in pedicle areas than in central and more oedematous areas ${ }^{(37)}$.

For the first time, we demonstrated that, in post-operative adhesions, reticulin was also found affected in extremely fibrotic areas. Regarding the ECM composition, laminin and type IV collagen were found in fibrotic regions of $\mathrm{S}$ and CRS but no significant difference with other diseases was found. Interestingly, in contrast with observations in asthma ${ }^{(38,39)}$, elastin seems also to resist better to fibrosis in upper airways and no major changes in the elastin network has been observed in $\mathrm{S}$. This suggests probable differences in protective actions supported by elastin in upper or lower airway diseases.

Finally, although upper airways can also be subject to major ECM reorganization ${ }^{(2)}$, this study has demonstrated that, in human, the gland integrity, absence of lymphoid follicles and limited neoangiogenesis should be considered as histomorphological markers of a healthy upper airway mucosa.

The study was limited to the pathological analysis and did not consider symptom severity, because all patients, after medical failure, were still presenting symptoms justifying surgery. For ethical reasons, we were not able to sample ethmoid tissue in controls: we considered nasal mucosa from the inferior turbinate 
as representative of the paranasal mucosa. The processes leading to these changes and the time sequence of development of these different remodelling aspects were not considered in this study. For example, oedema can rapidly be induced; the tissue development of fibrosis takes more time. This complex relationship was not specifically explored in this study. As for all mechanistic analysis, these in vivo results must be compared with caution to in vitro findings.

Another limit of this study is the poor specificity of HE staining for describing sub-populations of inflammatory cells but this analysis was not considered as a primary objective of the study.

\section{Conclusion}

Changes in ECM structures are common findings in chronic inflammatory diseases of upper airways, but rarely specific. Chronic rhinosinusitis with nasal polyps and post-operative adhesions present more oedematous and a trend to more fibrotic matrices, respectively. Epithelial shedding and thickening of basement membrane were not found different between the sub-groups of diseases.

\section{Authorship contribution}

\begin{tabular}{lllll|}
\hline Author & Design & $\begin{array}{c}\text { Data col- } \\
\text { lection }\end{array}$ & $\begin{array}{c}\text { Analysis and } \\
\text { interpreta- } \\
\text { tion }\end{array}$ & Manuscript \\
\hline De Coster & $\mathrm{X}$ & $\mathrm{X}$ & $\mathrm{X}$ & $\mathrm{X}$ \\
Eloy & $\mathrm{X}$ & $\mathrm{X}$ & & $\mathrm{X}$ \\
Ferdinande & & $\mathrm{X}$ & $\mathrm{X}$ & $\mathrm{X}$ \\
Taildeman & & $\mathrm{X}$ & $\mathrm{X}$ & $\mathrm{X}$ \\
Cuvelier & & $\mathrm{X}$ & $\mathrm{X}$ & $\mathrm{X}$ \\
Watelet & $\mathrm{X}$ & $\mathrm{X}$ & $\mathrm{X}$ & $\mathrm{X}$ \\
\hline
\end{tabular}

\section{Conflict of interest}

None

\section{REFERENCES}

1. Watelet JB, Van Cauwenberge P. Applied anatomy and physiology of the nose and paranasal sinuses. Allergy. 1999; 54 Suppl 57: 14-25.

2. Watelet JB, Van Zele T, Gjormarkaj M, et al. Tissue remodelling in upper airways: where is the link with lower airway remodelling? Allergy. 2006; 61: 1249-1258.

3. Redington AE. Fibrosis and airway remodelling. Clin Exp Allergy. 2000; 30 suppl 1: 42-45.

4. Bush A. How early do airway inflammation and remodeling occur. Allergology International. 2008; 57: 11-19.

5. Watelet JB, Demetter P, Claeys C, Van Cauwenberge $P$, Cuvelier C, Bachert C. Neutrophil-derived MMP-9 predicts the healing quality after sinus surgery. Laryngoscope. 2005; 115: 56-61.

6. James $A L$, Wenzel $S$. Clinical relevance of airway remodelling in airway diseases. Eur Respir J. 2007; 30: 134-155.

7. Norlander T, Westrin KM, Stierna P. The inflammatory response of the sinus and nasal mucosa during sinusitis: implications for research and therapy. Acta Otolaryngol Suppl. 1994; 515: 38-44.

8. Westrin KM, Stierna P, Carlsöö B, Hellström S. Mucosal fine structure in experimental sinusitis. Ann Otol Rhinol Laryngol. 1993; 102: 639-645

9. Pawankar R, Nonaka M. Inflammatory mechanisms and remodeling in chronic rhinosinusitis and nasal polyps. Curr Allergy Asthma Rep. 2007; 7: 202-208.

10. Timpl R, Rohde H, Robey PG, Rennard SI Foidart JM, Martin GR. Laminin - a glycoprotein from basement membranes. J Biol Chem. 1979; 254: 9933-9937.
11. Cherng S, Young J, Ma H. Alpha-Smooth Muscle Actin (a-SMA). J Am Sci. 2008; 4: 7-9.

12. Tuder RM, Groves B, Badesh DB, Voekel NF. Exuberant endothelial cell growth elements of inflammation are present in plexiform lesions of pulmonary hypertension. Am J Pathol. 1994; 144: 275-285.

13. Sumi Y, Hamid Q. Airway remodeling in asthma. Allergol Intern. 2007; 56: 341-348.

14. Bailey SR, Boustany S, Burgess JK, et al. Airway vascular reactivity and vascularisation in human chronic airway disease. Pulm Pharmacol Ther. 2009 22: 417-425.

15. Berger G, Berheim J, Ophir D. Epithelial shedding of the inferior turbinate in perennial allergic and nonallegric rhinitis: a riddle to solve. Arch Otolaryngol Head Neck Surg. 2007; 133: 78-82.

16. Schmidt J, Zalewski P, Olszewski J, Olszewska-Ziaber A. Histopathological verification of clinical indications to partial inferior turbinectomy. Rhinology. 2001; 39: 147-150.

17. Montero Mora P, Blanco E, Matta Campos JJ, Gonzales Espinosa A, Guidos Fogelbach G, Tinajeros Castañeda OA. Nasal remodelling in patients with perennial allergic rhinitis. Rev Alerg Mex. 2003; 50: 79-82.

18. Calderon-Garciduenas L, Rodriguez-Alcaraz A, Garcia R, et al. Human nasal mucosal changes after exposure urban pollution. Environ Health Perspect. 1994; 102: $1074-$ 1080.

19. Gevaert P, Holtappels G, Johansson SG, Cuvelier C, Van Cauwenberge P, Bachert C. Organization of secondary lymphoid tissue and local IgE formation to Staphylococcus aureus enterotoxins in nasal polyps. Allergy. 2005; 60: 71-79.
20. Mikko M, Fredriksson K, Wahlström J, Erikson P, Grunewald J, Sköld CM. Human T cells stimulate fibroblast-mediated degradation of extracellular matrix in vitro. Clin Exp Immunol. 2007; 151: 317-325.

21. Ponikau JU, Sherris DA, Kephart GM, et al. Features of airway remodeling and eosinophilic inflammation in chronic rhinosinusitis: is the histopathology similar to asthma? J Allergy Clin Immunol. 2003; 112: 877-882.

22. Sobol SE, Fukakusa M, Christodoulopoulos $P$, et al. Inflammation and remodelling of the sinus mucosa in children and adult with chronic sinusitis. Laryngoscope. 2003; 113: 410-414.

23. Rehl RM, Balla AA, Cabay RJ, Hearp ML, Pytynia KB, Joe SA. Mucosal remodeling in chronic rhinosinusitis. Am J Rhinol. 2007; 21: 651-657.

24. Ardehali MM, Amali A, Bakhshaee M, Madani Z, Amiri M. The comparison of histopathological characteristics of polyps in asthmatic and nonasthmatic patients. Otolaryngol Head Neck Surg. 2009; 140: 748-751.

25. Shahana S, Jaunmuktane Z, Stenkvist Asplund M, Roomans GM. Ultrastructural investigation of epithelial damage in asthmatic and non-asthmatic nasal polyps. Resp Med. 2006; 100: 2018-2028.

26. Janhke V, Theopold HM. Fine structure of nasal mucosa in mucoviscidosis, with special regard to polyposis. Laryngol Rhinol Otol. 1977; 56: 773-781.

27. Saitoh T, Kusunoki T, Yao T, et al. Relationship between epithelial damage or basement membrane thickness and eosinophilic infiltration in nasal polyps with chronic rhinosinusitis. Rhinology. 2009; 47: 275-279.

28. Saitoh T, Kusunoki T, Yao T, et al. Role of inter- 
leukin-17A in the eosinophil accumulation and mucosal remodeling in chronic rhinosinusitis with nasal polyps associated with asthma. Int Arch Allergy Immunol. 2010; 151: 8-16.

29. Kennedy DW, Senior BA, Gannon FH, Montone KT, Hwang P, Lanza DC. Histology and histomorphometry of ethmoid bone in chronic rhinosinusitis. Laryngoscope. 1998; 108: 502-507.

30. Beju D, meek WD, Kramer JC. The ultrastructure of the nasal polyps in patients with and without cystic fibrosis. J Submicrosc Cytol Pathol. 2004; 36: 155-165.

31. Van Zele T, Claeys S, Gevaert P, et al. Differentiation of chronic sinus diseases by measurement of inflammatory mediators. Allergy. 2006; 61: 1280-1289.

32. Bachert C, Gevaert P, Holtappels G, Cuvelier C, Van Cauwenberge P. Nasal polyposis: from cytokines to growth. Am J Rhinol. 2000; 14: 279-290.

33. Watelet JB, Bachert C, Claeys C, Van Cauwenberge P. Matrix metalloproteinases
MMP-7, MMP-9 and their tissue inhibitor TIMP-1: expression in chronic sinusitis vs nasal polyposis. Allergy. 2004; 59: 54-60.

34. Watelet JB, Claeys C, Perez-Novo C, Gevaert P, Van Cauwenberge P, Bachert C. Transforming Growth Factor-b1 in Nasal Remodeling: Differences between Chronic Rhinosinusitis and Nasal Polyposis. Am J Rhinol. 2004; 18: 267-272.

35. Ahmed SK, Williams JL, Drake-Lee A, Egginton S. No significant role for angiogenesis in nasal polyposis. Am J Rhinol. 2008; 22: 24-28.

36. Gosline JM, Rosenbloom J. Elastin. In Extracellular matrix biochemistry (KA Piez, Reddi AH, eds). New-York. Elsevier 1984.

37. Nishijima I, Sanai A, Yoshihara T. A relationship between mast cells and alphasmooth muscle actin-positive cells in the nasal polyps of chronic rhinosinusitis. Acta Otolaryngol Suppl. 2009; 562: 110-114

38. Mauad T, Xavier AC, Saldiva PH, Dolhikoff M. Elastosis and fragmentation of fibers of the elastic system in fatal asthma. Am J Resp Crit
Care Med. 1999; 160: 968-975.

39. Araujo BB, Silva LFF, Saldiva PHN, James AL, Dolhnikoff M, Mauad T. Elastin fiber content in airway smooth muscle in fatal asthma. Am Rev Respir Dis. 2005; 2: A516.

\section{Watelet JB, MD, PhD}

Department of Otorhinolaryngology Ghent University Hospital

De Pintelaan, 185

\section{Gent}

Belgium

Tel: +32-9-332 2332

Fax: +32-9-332 4993

E-mail: jeanbaptiste.watelet@ugent.be

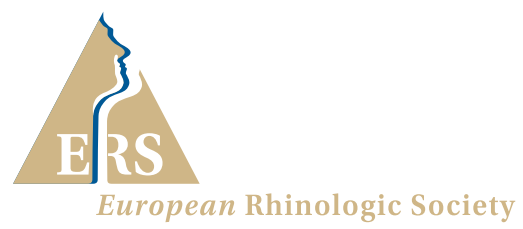

\section{ERS- Clinical-Research Grant 2013/2014}

In co-operation with the Foundation of Rhinology and Facial Plastic Surgery (RhiPla-Stiftung Ulm, Germany) the European Rhinologic Society offers financial support for clinical research in the field of rhinology. There is an increasing demand for evidence-based results of diagnostic and therapeutic procedures, in particular surgical interventions. This is why this specific grant aims to support controlled clinical studies in all fields of rhinology including surgery of the nose, sinuses and anterior skull base.

\section{The support amounts to $€ 10,000$, , in a 2 -years-period.}

It can be used for equipment, material or personnel. A preliminary report is asked after 1 year, a final report after 2 years. An oral report should be presented at the biannual ERS-Congresses.

Applicants should be ENT-specialists (age-limit 45 years) and members of ERS. Applications should be made on-line and include:

- CV and scientific background including previous publications and grants

- Affiliation and members of the working group

- Letter of recommendation from own head of department

- Title, concept and goals of the planned research-project

- Detailed description of the financial costing of the grant

Please send applications with the documents by email to: rhinologysecretary@amc.uva.nl 